\title{
Nordazepam Measurement
}

National Cancer Institute

\section{Source}

National Cancer Institute. Nordazepam Measurement. NCI Thesaurus. Code C139076.

The determination of the amount of nordazepam present in a sample. 